OPEN ACCESS

Edited by:

Paolo Marzullo,

Università degli Studi del Piemonte

Orientale, Italy

Reviewed by:

Valeria Guglielmi,

University of Rome Tor Vergata, Italy

Yoshifumi Saisho,

Keio University, Japan

Caterina Conte,

Università Telematica San Raffaele,

Italy

*Correspondence:

Elena Succurro

succurro@unicz.it

Specialty section:

This article was submitted to

Obesity,

a section of the journa

Frontiers in Endocrinology

Received: 30 September 2020

Accepted: 06 May 2021

Published: 24 May 2021

Citation:

Succurro E, Fraticelli $F$, Franzago $M$,

Fiorentino TV, Andreozzi F,

Vitacolonna E and Sesti G (2021)

Hyperglycemia at $1 \mathrm{~h}$-OGTT in

Pregnancy: A Reliable Predictor of

Metabolic Outcomes?

Front. Endocrinol. 12:612829.

doi: 10.3389/fendo.2021.612829

\section{Hyperglycemia at 1h-OGTT in Pregnancy: A Reliable Predictor of Metabolic Outcomes?}

\author{
Elena Succurro ${ }^{1 *}$, Federica Fraticelli ${ }^{2}$, Marica Franzago ${ }^{2}$, Teresa Vanessa Fiorentino ${ }^{1}$, \\ Francesco Andreozzi ${ }^{1}$, Ester Vitacolonna ${ }^{2}$ and Giorgio Sesti ${ }^{3}$ \\ ${ }^{1}$ Department of Medical and Surgical Sciences, University Magna Graecia of Catanzaro, Catanzaro, Italy, ${ }^{2}$ Department of \\ Medicine and Aging, School of Medicine and Health Sciences, 'G. d'Annunzio' University of Chieti-Pescara, Chieti, Italy, \\ ${ }^{3}$ Department of Clinical and Molecular Medicine, University of Rome-Sapienza, Rome, Italy
}

Gestational diabetes mellitus (GDM) is associated with a high risk of developing type 2 diabetes (T2DM) and cardiovascular disease (CVD). Identifying among GDM women those who are at high risk may help prevent T2DM and, possibly CVD. Several studies have shown that in women with GDM, hyperglycemia at $1 \mathrm{~h}$ during an oral glucose tolerance test (OGTT) (1-h PG) is not only associated with an increase in adverse maternal and perinatal outcomes but is also an independent predictor of T2DM. Interestingly, also in pregnant women who did not meet the criteria for a GDM diagnosis, 1-h PG was an independent predictor of postpartum impaired insulin sensitivity and beta-cell dysfunction. Moreover, maternal 1- and 2-h PG levels have been found to be independently associated with insulin resistance and impaired insulin secretion also during childhood. There is evidence that hyperglycemia at $1 \mathrm{~h}$ PG during pregnancy may identify women at high risk of future CVD, due to its association with an unfavorable CV risk profile, inflammation, arterial stiffness and endothelial dysfunction. Overall, hyperglycemia at $1 \mathrm{~h}$ during an OGTT in pregnancy may be a valuable prediction tool for identifying women at a high risk of future T2DM, who may then benefit from therapeutic strategies aimed at preventing cardiovascular outcomes.

Keywords: type 2 diabetes, cardiovascular disease, prediabetes, biomarkers, oral glucose tolerance test, hyperglycemia, gestational diabetes

\section{INTRODUCTION}

Gestational diabetes mellitus (GDM) is a clinical condition characterized by a pancreatic beta-cell dysfunction responsible for an insufficient insulin secretion that is unable to compensate for the progressive insulin resistance that characterizes the latter half of gestation $(1,2)$.

Women with GDM present up to seven-fold higher risk of developing type 2 diabetes (T2DM) and a two-fold greater risk of developing cardiovascular disease (CVD) than women with normoglycemia during pregnancy (3-10).

Identifying among GDM women those at high risk may help prevent T2DM and, possibly, CVD.

In the last decade, a large body of evidence has accumulated showing that the 1-h post-load glucose concentration (1-h PG) may be a useful early biomarker of dysglycemia (11). To detect 
specifically impaired glucose tolerance (IGT), the National Diabetes Data Group in 1979 required an interim OGTT glucose level $>200 \mathrm{mg} / \mathrm{dl}(11.1 \mathrm{mmol} / \mathrm{L})$ at 30, 60, or $90 \mathrm{~min}$. In addition, the fasting plasma glucose (FPG) needed to be below the diagnostic threshold for diabetes (FPG $>140 \mathrm{mg} / \mathrm{dl}[7.8 \mathrm{mmol} / \mathrm{L}]$ ) and a 2 -h value $>140 \mathrm{mg} / \mathrm{dl}(7.8 \mathrm{mmol} / \mathrm{L})$ and $<200 \mathrm{mg} / \mathrm{dl}(11.1$ $\mathrm{mmol} / \mathrm{L})]$ (12). Due to the difficulty of measuring interim glucose levels, the World Health Organization and the American Diabetes Association (ADA) abandoned the diagnostic use of the 1-h PG recommending the $2-\mathrm{h} P \mathrm{PG}$ as the only post-load value required for diagnosis of IGT. Nevertheless, the measurement of 1-h PG has remained a criterion for detecting GDM.

In this review, a literature search was performed in order to examine the impact of elevated PG values during OGTT and the occurrence of T2DM in women with GDM. Furthermore, the available literature regarding the association between PG values during an OGTT in pregnancy and future cardiometabolic risk was examined (Table 1).

\section{H-OGTT IN PREGNANCY AND MATERNAL AND NEONATAL OUTCOMES}

Numerous studies have provided evidence for an independent association between PG levels during an OGTT in pregnancy and adverse maternal and neonatal outcomes (10,28-31). In this scenario, the glucose value at $1 \mathrm{~h}$ during an OGTT may represent a useful early biomarker to recognize women with worse adverse outcomes.

The Hyperglycemia and Adverse Pregnancy Outcome (HAPO) study, a clinical trial conducted on a large cohort of pregnant women, showed a highly significant association between maternal fasting and post-load glucose values and increased birth weight as well as higher cord-blood serum Cpeptide levels (28). Moreover, premature delivery, intensive neonatal care, and hyperbilirubinemia were significantly related to 1- and 2-h PG levels but not to FPG. Remarkably, 1h PG was a significant independent predictor of clinical neonatal hypoglycemia (28). Similarly, in a study of 5,019 pregnant women, Kim et al. showed that women with elevated 1-h PG levels exhibited increased adverse outcomes if compared with women with normal OGTT values or women with elevated 2and 3-h PG (29). Likewise, in pregnant Caucasian women, elevated FPG and hyperglycemia at $1 \mathrm{~h}$ during an OGTT were associated with a high prevalence of adverse obstetric outcomes, including caesarean delivery, macrosomia, and hypertensive disorder, whereas elevated 2- or 3-h PG did not exhibit significant differences than control group (30).

In the HAPO cohort, it has been shown that in addition to glucose levels also maternal metabolome was associated with

TABLE 1 | Studies evaluating cardiometabolic risk in women with hyperglycemia at 1-h during an OGTT in pregnancy.

\begin{tabular}{|c|c|c|c|c|}
\hline Study & Study design & Number of participants & $\begin{array}{l}\text { Geographical } \\
\text { location }\end{array}$ & Key outcomes \\
\hline Buchannan et al. (10) & Longitudinal study & 91 Latino women with GDM & Los Angeles, USA & 1-h PG predictor of diabetes at 1-2 years after pregnancy \\
\hline Lee et al. (13) & Retrospective study & 5,470 women with GDM & Melbourne, Australia & 1-h PG predictor of diabetes at 15 years after pregnancy \\
\hline Wein et al. (14) & Longitudinal study & 2,957 women with GDM & Melbourne, Australia & 1-h PG predictor of diabetes at 6 months after pregnancy \\
\hline Retnakaran et al. (15) & Longitudinal study & 412 pregnant women & Toronto, Canada & $\begin{array}{l}\text { 1-h PG predictor of prediabetes/diabetes after } 3 \text { months } \\
\text { after pregnancy }\end{array}$ \\
\hline Nishikawa et al. (16) & Retrospective study & 185 women with GDM & Japan & $\begin{array}{l}\text { 1-h PG predictor of impaired glucose tolerance after 6-12 } \\
\text { weeks after pregnancy }\end{array}$ \\
\hline Di Cianni et al. (17) & Cross-sectional study & 4,053 pregnant women & Tuscany, Italy & $\begin{array}{l}\text { Independent association between 1-h PG and reduced } \\
\text { insulin secretion }\end{array}$ \\
\hline Ghio et al. (18) & $\begin{array}{l}\text { Observational cross- } \\
\text { sectional study }\end{array}$ & 4,053 pregnant women & Tuscany, Italy & $\begin{array}{l}\text { Progressive increase in 1-h PG levels was associated with } \\
\text { both } \beta \text {-cell dysfunction and insulin resistance }\end{array}$ \\
\hline Leopold et al. (19) & Longitudinal study & 930 pregnant women & Vienna, Austria & $\begin{array}{l}\text { Independent association between elevated 1-h PG and } \\
\text { cord blood insulin levels and intrapartum hyperinsulinism }\end{array}$ \\
\hline Retnakaran et al. (20) & Cross-sectional study & 180 pregnant women & Toronto, Canada & $\begin{array}{l}\text { Greater independent association between 1-h PG and } \\
\text { hyperglycemia and insulin resistance than 2- or 3-h PG }\end{array}$ \\
\hline Retnakaran et al. (21) & Cross-sectional study & 361 pregnant women & Toronto, Canada & $\begin{array}{l}\text { Independent association between } 1 \text {-h PG and } \\
\text { hyperglycemia, insulin resistance and } \beta \text {-cell dysfunction } \\
\text { after } 3 \text { months post-partum }\end{array}$ \\
\hline $\begin{array}{l}\text { Scholtens et al. HAPO } \\
\text { FUS (22) }\end{array}$ & Longitudinal study & $\begin{array}{l}\text { 4,832 children whose } \\
\text { mothers were in HAPO study }\end{array}$ & $\begin{array}{l}\text { International, } \\
\text { multicentric study }\end{array}$ & $\begin{array}{l}\text { Independent association between maternal glucose levels } \\
\text { and higher glucose levels and insulin resistance during } \\
\text { childhood }\end{array}$ \\
\hline Lekva et al. (23) & Prospective cohort study & 300 pregnant women & Oslo, Norway & $\begin{array}{l}\text { 1- and 2-h PG predictor of arterial stiffness after } 5 \text { years of } \\
\text { follow-up }\end{array}$ \\
\hline Retnakaran et al. (24) & Prospective cohort study & 485 pregnant women & Toronto, Canada & $\begin{array}{l}\text { 1h-PG predictor of unfavorable CV profile risk after } 3 \\
\text { months post-partum }\end{array}$ \\
\hline Gungor et al. (25) & Cross-sectional study & 51 pregnant women & Canakkale, Turkey & $\begin{array}{l}\text { Direct correlations between 1- and 2-h PG and impaired } \\
\text { endothelial function }\end{array}$ \\
\hline Gobl et al. (26) & Longitudinal study & 110 women with prior GDM & Vienna, Austria & $\begin{array}{l}\text { 1-h PG predictor of diabetes after } 10 \text { years after } \\
\text { pregnancy Association between 1-h PG and subclinical } \\
\text { inflammation and adhesion molecules }\end{array}$ \\
\hline Tumminia et al. (27) & Retrospective study & 297 women with GDM & Catania, Italy & 1-h PG predictor post-partum 1-h OGTT $\geq 155$ mg/dl \\
\hline
\end{tabular}


maternal insulin resistance and newborn outcomes (31). In particular, at $1 \mathrm{~h}$ during an OGTT several fatty acids, triacylglycerols, amino acids, acylcarnitines, and their metabolites were associated with newborn outcomes, including adiposity and high cord C-peptide, suggesting that maternal metabolites may contribute to fetal growth and adiposity, independent of maternal BMI and glucose levels (31).

This report is in keeping with a study of 930 pregnant women, in which it has been shown that 1-h PG values between 160 and $179 \mathrm{mg} / \mathrm{dl}$ were significantly associated with increased cordblood insulin levels, intrapartum hyperinsulinism, and macrosomia, compared to a value of 1-h PG below $160 \mathrm{mg} / \mathrm{dl}$ (19). Likewise, Mello et al. reported a significant association between 1-h PG levels and abnormal neonatal anthropometric features in pregnant women who did not meet the criteria for a GDM diagnosis (32). In particular, they found an inflection point for a threshold 1-h value of $160 \mathrm{mg} / \mathrm{dl}$ in late pregnancy in the ROC curve for the prediction of abnormal neonatal anthropometric characteristics (OR for 1-h glucose load values $>160 \mathrm{mg} / \mathrm{dl}$ was 67.4 (CI, 32.1-141.2); sensitivity, 68.8\%, specificity 99.02\%) (32). These results are consistent with threshold of $160 \mathrm{mg} / \mathrm{dl}$ for 1-h PG values established by Weiss to define an increased risk of fetal hyperinsulinemia (33).

Overall, besides demonstrating the independent association between hyperglycemia at $1 \mathrm{~h}$ during an OGTT below the threshold values for the diagnosis of GDM and adverse outcomes, these data suggest that a threshold of $160 \mathrm{mg} / \mathrm{dl}$ for $1 \mathrm{~h}$ during OGTT may be adopted in order to identify women with an increased risk of fetal hyperinsulinemia and, consequently, at a high risk of adverse clinical outcomes. Indeed, as suggested by Desoye and Nolan (34) fetal hyperinsulinemia lowering fetal glucose levels may increase the glucose concentration gradient across the placenta and, consequently, the glucose flux to the fetus. An exaggerated glucose steal due to fetal hyperinsulinemia could also reduce maternal glucose levels and mask GDM diagnosis during OGTT (34).

\section{H-OGTT IN PREGNANCY AND PREDICTION OF TYPE 2 DIABETES}

Several studies suggest that 1 -h PG during an OGTT in pregnancy may be considered a relevant marker for improving metabolic risk stratification in women with GDM (10, 13-18, 20). Notably, in a longitudinal study performed on 91 Latino women with GDM, 1-h PG was the strongest independent predictor of T2DM at 1-2 years after pregnancy (10). Additionally, compared to women in the lowest tertile of 1-h PG, women in the highest tertile had a 15 -fold greater risk of developing T2DM, after adjustment for insulin secretion and insulin sensitivity (10). Consistent with these data, in an analysis carried out in 5.470 women with GDM, among the glycemic parameters measured, only $1-\mathrm{h}$ PG level was an independent predictor of T2DM at 15 years of follow-up (13). In particular, for each $1 \mathrm{mmol} / \mathrm{L}$ increase of 1 -h PG levels, the rate of type 2 diabetes increased by 1.3 times. Neither fasting nor 2 -h post-load glucose levels were found to be independent risk factors of later development of T2DM (13). Similar results were observed in a longitudinal study carried out in 2,957 women with GDM from different ethnicities, in which 1-h PG level, and not fasting or 2-h PG, was an independent predictor of postpartum T2DM (for every $1 \mathrm{mmol} / \mathrm{L}$ increase of 1 -h PG level, the odds of T2DM increased by $47 \%$ ) ( $1 \mathrm{~h}$ : HR, 1.3; 95\% CI, 1.2-1.4; P<0.001; FPG: HR, 1.00; 95\% CI, 0.9-1.1, P>0.1; 2 h: HR, 1.00; 95\% CI, 0.9-1.1; $\mathrm{P}>0.1$ ) (14). Physiologically, the $1-\mathrm{h}$ PG reflects first-phase insulin release, which is believed to be defective in GDM and type 2 diabetic patients, thus explaining its stronger predictive value in assessing the risk of T2DM development $(13,14)$.

Retnakaran et al. showed that in 412 pregnant women from different ethnicities, 1, 2, and $3 \mathrm{~h}$ post-load glucose levels were independent predictors of postpartum glucose intolerance even after adjustment for various risk factors for diabetes $(1 \mathrm{~h}$ : OR, 1.31 ; 95\% CI, 1.09-1.57; P = 0.0036; 2 h: OR, 1.54; 95\% CI, $1.28-$ $1.84 ; \mathrm{P}<0.0001 ; 3$ h: OR, 1.30; 95\% CI, 1.09-1.55; $\mathrm{P}=0.0030$ ), whereas FPG was a significant predictor of only large for gestational age (LGA) (15). Furthermore, whereas FPG had the highest area under the ROC curve (AROC) for predicting LGA (0.62), the 1- and 2-h PG had the highest AROC values for postpartum prediabetes/diabetes ( 0.68 and 0.72 , respectively), reflecting the superior discriminative capacity of post-load glucose values in the prediction of postpartum glucose intolerance (15). Similarly, in a study conducted on Japanese women, it has been shown that 1-h PG levels during an OGTT at diagnosis of GDM were significant predictors for both the need for insulin therapy in pregnancy and postpartum IGT (1 h: OR, 1.023; 95\% CI, 1.009-1.037; P = 0.001; 1 h: OR, 1.027; 95\% CI, 1.004-1.050; $\mathrm{P}=0.002$, respectively) (16). Moreover, the cutoff value of plasma glucose levels at $1 \mathrm{~h}$ during an OGTT for postpartum IGT was $184.5 \mathrm{mg} / \mathrm{dl}$ (AUC, 0.770 ; sensitivity of $68.0 \%$; specificity of $82.3 \%$ ). On the contrary, 2-h PG levels were not found significant predictors of postpartum IGT $(2 \mathrm{~h}$ : OR, 1.001; 95\% CI, 0.980-1.023; P = 0.9) (16).

Taken together, these results suggest that elevated 1-h PG levels in women with GDM may be a valuable prediction tool for identifying women at risk for future T2DM.

\section{H-OGTT IN PREGNANCY AND METABOLIC DYSFUNCTION}

It has been suggested that among glycemic parameters, 1-h PG may reflect greater insulin resistance and beta cell dysfunction (17-21, 35). In a study involving 4.053 pregnant women, Di Cianni et al. reported that elevated 1-h PG levels were independently associated with a reduction of insulin secretion, assessed by an insulin secretion-sensitivity index, as compared with elevated FPG and 2- or 3-h PG (17). Moreover, another study conducted in the same large cohort showed that the progressive increase in $1-\mathrm{h}$ PG levels was associated with a progressive loss of $\beta$-cell function as well as a decline in insulin sensitivity (18). In particular, for each $20 \mathrm{mg} / \mathrm{dl}$ 
increase in 1-h PG levels there was a concomitant impairment in insulin action and a reduction in insulin secretion. In addition, in women with 1 -h PG $<180 \mathrm{mg} / \mathrm{dl}$, the progressive nature of defects in insulin secretion (HOMA-B: -29.7\%) and insulin sensitivity (HOMA-IR: $+15 \%$ ) was still apparent (all $\mathrm{P}<0.001$ ), with a significant impairment in women with $1-\mathrm{h}$ PG $>160 \mathrm{mg} / \mathrm{dl}$ (18). These results were consistent with a study of 180 Caucasian, Asian, South Asian pregnant women in which elevated 1-h PG level was independently associated with greater hyperglycemia and higher insulin resistance than elevated 2- or 3-h PG (20). Furthermore, the metabolic phenotype associated with hyperglycemia at $1 \mathrm{~h}$ post-load resembles that of GDM, whereas that for hyperglycemia at 2 or $3 \mathrm{~h}$ post-load exhibits similarity to that of normotolerant women. Moreover, 1-h PG level during an OGTT was associated with lower adiponectin concentration than 2or 3-h PG (20). Adiponectin is an adipocyte-derived hormone exerting insulin sensitizing effects whose reduction has been associated with an increased risk of T2DM (20).

Consistent with these data, Retnakaran et al. showed that elevated 1-h PG levels during pregnancy were associated with a significant metabolic dysfunction not only during pregnancy, but also at 3 months postpartum, including increased insulin resistance, and poorer $\beta$-cell function (21). Specifically, in contrast to elevated 2- or 3-h PG levels, hyperglycemia at $1 \mathrm{~h}$ during an OGTT bears metabolic resemblance to GDM not only during pregnancy, but also later during the postpartum period where elevated 1-h PG levels remain associated with increased glycemia, insulin resistance, and $\beta$-cell dysfunction (21). Moreover, 1-h PG levels during an OGTT was an independent negative predictor of $\beta$-cell dysfunction at 3 months postpartum $(\mathrm{t}=-3.79, \mathrm{P}=0.0002)(21)$, even in pregnant women with normal glucose tolerance (35).

As recently demonstrated by an analysis of the HAPO Follow-Up Study, maternal glucose levels were associated with higher glucose levels and insulin resistance during childhood, independently of maternal and child body mass index (BMI) (22). Notably, maternal FPG was associated with child impaired fasting glucose (IFG), and 1- and 2-h PG during an OGTT in pregnancy were associated with child IGT. In addition, FPG, 1-, and 2-h PG in pregnancy were inversely associated with child insulin sensitivity, whereas 1 - and 2-h PG were inversely associated with insulin secretion (22). These data suggest that children exposed in utero to higher glucose levels may be at higher risk for dysglycemic conditions associated with impaired insulin secretion and altered insulin action over time.

Moreover, in recent analyses of the HAPO Study and HAPO Follow-up Study, it has been shown that newborn adiposity is independently associated with childhood adiposity, and, along with fetal hyperinsulinemia, mediates associations of maternal glucose and BMI with childhood adiposity (36).

Taken together, these data suggest that a loss of $\beta$-cell function as well as a decline in insulin sensitivity have been found also in women with glucose levels below the threshold values for the diagnosis of GDM (18). A threshold of $160 \mathrm{mg} / \mathrm{dl}$ for $1 \mathrm{~h}$ during an OGTT may be useful to identify women with defects insulin sensitivity and insulin secretion who are at a high risk of postpartum metabolic dysfunction. Furthermore, this 1hOGTT threshold may help to detect fetal hyperinsulinemia and, consequently, childhood adiposity $(18,19,32,33,36)$.

\section{H-OGTT IN PREGNANCY AND CARDIOVASCULAR RISK}

Women with previous GDM ( $\mathrm{p}-\mathrm{GDM}$ ) have an increased lifetime risk of developing $\operatorname{CVD}(4,5,8,9)$. Interestingly, also in pregnant women who did not meet the criteria for a GDM diagnosis, 1-h PG was associated with an increased cardiovascular risk (24). In a prospective study, it has been shown that, among women without GDM, those with hyperglycemia at $1 \mathrm{~h}$ during an OGTT exhibited a worse CV risk profile at 3 months post-partum than women exhibiting elevated 2- and 3-h PG levels, suggesting that 1-h PG levels could capture an unrecognized patient population at risk for CVD (24).

Moreover, Lekva et al. found that 1- and 2-h PG levels were predictor of high pulse wave velocity (PWV) after 5 years of follow-up (23). It is known that high PWV reflects increased arterial stiffness, a strong predictor of future CV events (37). Accordingly, Gungor et al showed that both GDM and impaired glucose metabolism in pregnancy were associated with endothelial dysfunction, and that endothelial dysfunction was a significantly correlated with 1 - and 2-h PG during an OGTT (25).

\section{H-OGTT IN PREGNANT WOMEN AFTER BARIATRIC SURGERY: A BETTER RELIABLE MARKER THAN 2H-OGTT?}

Maternal BMI represents an additional risk factor of progression to postpartum T2DM and CVD. As observed by Liu et al., prepregnancy $\mathrm{BMI} \geq 30 \mathrm{~kg} / \mathrm{m}^{2}$ conferred a 6.54 -fold higher risk of developing T2DM, and a 1.79-fold higher risk of developing prediabetes than women with $\mathrm{BMI}<23 \mathrm{~kg} / \mathrm{m}^{2}$ (38).

It has been reported that maternal p-GDM as well as prepregnancy or postpartum obesity increased by 50 -fold the risk of T2DM and hyperglycemia than women without obesity and GDM (39).

A large prospective cohort study showed that bariatric surgery was associated with lower risk of GDM, and large for gestational age infants, as well as with an increased risk of smallfor-gestational-age infants, and, possibly, an increased stillbirth or neonatal death (40). However, the diagnosis of GDM was made according to FPG and 2-h PG levels during an OGTT, without considering 1 -h PG values. The use of 2 -h glucose values during an OGTT routinely performed also in other studies might be considered inappropriate to detect hyperglycemia in pregnant women after bariatric surgery $(41,42)$. Indeed, a history of gastric bypass surgery can influence the results of the OGTT recommended during pregnancy. Women after bariatric surgery had lower FPG levels as compared with lean, women with 
obesity, and BMI-matched controls, and showed altered postprandial glucose kinetics, including a rise at $1 \mathrm{~h}$ followed by hypoglycemia. The GDM incidence was lower in gastric bypass patients when FPG and 2-h PG levels (and not 60 min glucose levels) were used to classify hyperglycemia, while there was a markedly increased incidence of GDM when also 1-h PG levels were considered for diagnosis (42). In case of dumping syndrome or rapid gastric emptying, the conventional OGTT test should be avoided, and serial capillary glucose monitoring before and after meals should be used as an alternative, paying particular consideration to the value at $1 \mathrm{~h}$ after meals for a week at 24 to 28 weeks' gestation $(43,44)$. These data suggest that the detection of the plasma glucose value at $1 \mathrm{~h}$ may be a better predictive parameter for cardiometabolic outcomes in pregnant women after bariatric surgery.

\section{H-OGTT AFTER PREGNANCY AND CARDIOMETABOLIC PREDICTION}

It has been shown that hyperglycemia at $1 \mathrm{~h}$ during an OGTT after pregnancy may contribute to risk stratification of women with p-GDM (26). Gobl et al. reported that, in women with pGDM, 1-h PG levels were a better predictor for insulin sensitivity and insulin secretion at 3-6 months after delivery compared to other time points during an OGTT (26). In addition, 1-h PG levels were significantly related with an increased risk of diabetes over 10 years of follow-up (HR, 1.63; 95\% CI, 1.36-1.97, $\mathrm{P}<0.001)(26)$.

Overall, accrued data on the impact of hyperglycemia at $1 \mathrm{~h}$ during an OGTT in GDM are consistent with those observed in general population suggesting that 1-h hyperglycemia during an OGTT is an independent predictor for future T2DM (11, 45-51). Indeed, in 2007 Abdul-Ghani et al. showed that PG value at $1 \mathrm{~h}$ during an OGTT was a better predictor for future T2DM than FPG or 2-h PG values (45). In the San Antonio Heart Study, a cutoff of $155 \mathrm{mg} / \mathrm{dl}$ for the 1-h post-load PG was successfully identified to detect a group of normal glucose-tolerant (NGT) subjects who were at risk for T2DM (46). Subsequently, these data were confirmed by several longitudinal studies in different ethnic groups as well as in a meta-analysis of prospective studies showing that NGT subjects with 1 -h post-load glucose $>155 \mathrm{mg}$ / dl (NGT 1 h-high) have a four-fold increased risk to develop T2DM [OR 4.33 95\% CI 3.40 to 5.51] (11, 47-51).

It has been reported that in women with GDM hyperglycemia at $1 \mathrm{~h}$ during an OGTT was an independent predictor of postpartum NGT 1h-high (27). Indeed, women with high 1h-OGTT values during pregnancy had a 3.7-fold increased risk to have high 1-h OGTT values after pregnancy than those with normal 1h-OGTT value. In addition, women with NGT $1 \mathrm{~h}$ high exhibited an impaired insulin secretion and greater insulin resistance already during pregnancy than NGT women with 1h-OGTT low (27). Similar results have been observed in general population as several studies have shown that subjects with NGT 1h high exhibit impaired peripheral insulin action and beta-cell dysfunction (52-55). Interestingly, it has been shown that both
1- and 2-h PG levels, but not FPG, were independently associated with myocardial insulin resistance, suggesting a role of post-load hyperglycemia in determining development of CVD (55).

Additionally, it has been reported a significant association between 1-h PG levels during pregnancy and markers of subclinical systemic inflammation such as high sensitive Creactive protein $(\mathrm{r}=0.43, \mathrm{P}<0.001)$ as well as markers of endothelial dysfunction including plasminogen activator inhibitor $1(\mathrm{r}=0.36, \mathrm{P}<0.001)$, tissue plasminogen activator ( $\mathrm{r}=0.40, \mathrm{P}<0.001)$, endothelial-leukocyte adhesion molecule 1 $(\mathrm{r}=0.32, \mathrm{P}<0.001)$, and intercellular adhesion molecule (ICAM)$1(\mathrm{r}=0.37, \mathrm{P}<0.001)(56)$.

In general population hyperglycemia at $1 \mathrm{~h}$ during an OGTT has been associated with CV subclinical organ damage, such as endothelial dysfunction, arterial stiffness, early atherosclerosis and with an unfavorable cardiometabolic risk profile, including worse lipid profile, adiposity and inflammatory markers $(11,27$, 46, 50-60), an increased risk of developing CVD and all-cause mortality $(51,57)$. Moreover, in NGT subjects the 1-h PG concentration $>155 \mathrm{mg} / \mathrm{dl}$ was independently associated with an $28 \%$ increased risk of all-cause mortality during a 33-year follow-up than subjects with low 1-h PG (57). Taken together with the data reported in pregnancy and in women with $\mathrm{p}-\mathrm{GDM}$, it is tempting to suggest that hyperglycemia at $1 \mathrm{~h}$ during an OGTT may identify a sizable proportion of subjects, who are at increased risk to develop T2DM, and its related cardiovascular complications.

\section{CONCLUSIONS}

Prior literature has focused enormously on the risk of developing T2DM later in life in women with $\mathrm{p}-\mathrm{GDM}$, considering pregnancy as a possible stress test for the beta-cells (4). Over the last decades, several studies have observed the relationship between GDM and future risk of CVD, highlighting the importance of early preventive intervention, as well as the promotion of a healthy lifestyle $(4,9,61)$.

Identifying among women with GDM those at high risk for adverse cardiometabolic outcomes may help prevent T2DM and its related $\mathrm{CV}$ complications. Examination of $\mathrm{PG}$ values at different times during an OGTT could provide useful information for the identification of women at high risk for T2DM.

Several studies have provided evidence for an independent predictive role of the glucose value at $1 \mathrm{~h}$ during an OGTT in the recognition of women at worse maternal and neonatal outcomes (19, 28-33). Interestingly, an independent association between hyperglycemia at $1 \mathrm{~h}$ during an OGTT and adverse maternal and perinatal outcomes has been found also in women with glucose levels below the threshold values for the diagnosis of GDM. These findings raise the possibility that adopting a lower threshold value at $1 \mathrm{~h}$ during OGTT $(160 \mathrm{mg} / \mathrm{dl})$ may be useful to identify women with an increased risk of fetal hyperinsulinemia and, consequently, at high risk of adverse clinical outcomes $(19,32,33)$. 
It has been shown that among glycemic parameters elevated 1-h PG levels may be a more sensitive prediction tool for identifying the women with GDM at risk for future T2DM, which could benefit from preventative measures $(10,13-18,20)$. Additionally, hyperglycemia at 1-h PG during an OGTT may be considered a relevant biomarker for identifying pregnant women with insulin resistance, $\beta$-cell dysfunction and fetal hyperinsulinism, and with an unfavorable cardiovascular profile at post-partum (10,17-21, 35). Moreover, maternal 1and 2-h PG levels were also associated with child insulin resistance and impaired insulin secretion, suggesting that children exposed in utero to higher glucose levels may be at higher risk for progression to T2DM (22).

Furthermore, it has been shown that hyperglycemia at $1 \mathrm{~h}$ during an OGTT in pregnancy may identify women at high risk of future CVD, who may benefit from surveillance and modification of CV risk factors $(23,24,37)$. These data are in agreement with robust evidence gathered in general population

\section{REFERENCES}

1. Buchanan TA, Xiang A, Kjos SL, Watanabe R. What is Gestational Diabetes? Diabetes Care (2007) 30:S105-111. doi: 10.2337/dc07-s201

2. Buchanan TA. Pancreatic Beta-Cell Defects in Gestational Diabetes: Implications for the Pathogenesis and Prevention of Type 2 Diabetes. J Clin Endocrinol Metab (2001) 86:989-93. doi: 10.1210/jcem.86.3.7339

3. Bellamy L, Casas JP, Hingorani AD, Williams D. Type 2 Diabetes After Gestational Diabetes a Systematic Review and Meta-Analysis. Lancet (2009) 373:1773-9. doi: 10.1016/S0140-6736(09)60731-5

4. Retnakaran R. Hyperglycemia in Pregnancy and its Implications for a Woman's Future Risk of Cardiovascular Disease. Diabetes Res Clin Pract (2018) 145:193-9. doi: 10.1016/j.diabres.2018.04.008

5. Brewster S, Zinman B, Retnakaran R, Floras JS. Cardiometabolic Consequences of Gestational Dysglycemia. J Am Coll Cardiol (2013) 62:677-84. doi: 10.1016/j.jacc.2013.01.080

6. Buchanan TA, Xiang AH, Page KA. Gestational Diabetes Mellitus: Risks and Management During and After Pregnancy. Nat Rev Endocrinol (2012) 8:63949. doi: 10.1038/nrendo.2012.96

7. Damm P, Kühl C, Bertelsen A, Mølsted-Pedersen L. Predictive Factors for the Development of Diabetes in Women With Previous Gestational Diabetes Mellitus. Am J Obstet Gynecol (1992) 167:607-16. doi: 10.1016/S0002-9378 (11)91559-2

8. Shah BR, Retnakaran R, Booth GL. Increased Risk of Cardiovascular Disease in Young Women Following Gestational Diabetes Mellitus. Diabetes Care (2008) 31:1668-9. doi: 10.2337/dc08-0706

9. Tobias DK, Stuart JJ, Li S, Chavarro J, Rimm EB, Rich-Edwards J, et al. Association of History of Gestational Diabetes With Long-Term Cardiovascular Disease Risk in a Large Prospective Cohort of US Women. JAMA Intern Med (2017) 177:1735-42. doi: 10.1001/jamainternmed.2017.2790

10. Buchanan TA, Xiang AX, Kjos SL, Trigo E, Lee WP, Peters RK. Antepartum Predictors of the Development of Type 2 Diabetes in Latino Women 11-26 Months After Pregnancies Complicated by Gestational Diabetes. Diabetes (1999) 48:2430-6. doi: 10.2337/diabetes.48.12.2430

11. Fiorentino TV, Marini MA, Succurro E, Andreozzi F, Perticone M, Hribal ML, et al. One-Hour Postload Hyperglycemia: Implications for Prediction and Prevention of Type 2 Diabetes. J Clin Endocrinol Metab (2018) 103:3131-43. doi: $10.1210 /$ jc.2018-00468

12. National Diabetes Data Group. Classification and Diagnosis of Diabetes Mellitus and Other Categories of Glucose Intolerance. Diabetes (1979) 28:1039-57. doi: 10.2337/diab.28.12.1039

13. Lee AJ, Hiscock RJ, Wein P, Walker SP, Permezel M. Gestational Diabetes Mellitus: Clinical Predictors and Long-Term Risk of Developing Type 2 Diabetes: A Retrospective Cohort Study Using Survival Analysis. Diabetes Care (2007) 30:878-83. doi: 10.2337/dc06-1816 showing that hyperglycemia at $1 \mathrm{~h}$ during an OGTT is an independent predictor for T2DM, CVD, and all-cause mortality $(11,27,46-57)$.

Further prospective studies with larger cohorts are needed in order to evaluate whether lifestyle changes may help these women to prevent clinical adverse outcomes and reduce the risk of future T2DM and CVD.

\section{AUTHOR CONTRIBUTIONS}

ES wrote and edited the manuscript. FF, MF, TF, and FA researched data and reviewed the manuscript. EV wrote and reviewed the manuscript. GS wrote and reviewed the manuscript. GS is the guarantor of the study, conceived the study, and takes full responsibility for the work. All authors contributed to the article and approved the submitted version.

14. Wein P, Beischer NA, Sheedy MT. Studies of Postnatal Diabetes Mellitus in Women Who had Gestational Diabetes. Part 2. Prevalence and Predictors of Diabetes Mellitus After Delivery. Aust N Z J Obstet Gynaecol (1997) 37:420-3. doi: 10.1111/j.1479-828X.1997.tb02450.x

15. Retnakaran R, Qi Y, Sermer M, Connelly PW, Hanley AJ, Zinman B. The Antepartum Glucose Values That Predict Neonatal Macrosomia Differ From Those That Predict Postpartum Prediabetes or Diabetes: Implications for the Diagnostic Criteria for Gestational Diabetes. J Clin Endocrinol Metab (2009) 94:840-5. doi: 10.1210/jc.2008-2434

16. Nishikawa T, Ono K, Hashimoto S, Kinoshita H, Watanabe T, Araki H, et al. One-hour Oral Glucose Tolerance Test Plasma Glucose At Gestational Diabetes Diagnosis is a Common Predictor of the Need for Insulin Therapy in Pregnancy and Postpartum Impaired Glucose Tolerance. J Diabetes Investig (2018) 9:1370-7. doi: 10.1111/jdi.12848

17. Di Cianni G, Seghieri G, Lencioni C, Cuccuru I, Anichini R, De Bellis A, et al. Normal Glucose Tolerance and Gestational Diabetes Mellitus: What is in Between? Diabetes Care (2007) 30:1783-8. doi: 10.2337/dc07-0119

18. Ghio A, Seghieri G, Lencioni C, Anichini R, Bertolotto A, De Bellis A, et al. 1Hour OGTT Plasma Glucose as a Marker of Progressive Deterioration of Insulin Secretion and Action in Pregnant Women. Int J Endocrinol (2012) 2012:460509. doi: 10.1155/2012/460509

19. Leipold H, Kautzky-Willer A, Ö zbal A, Bancher-Todesca D, Worda C. Fetal Hyperinsulinism and Maternal One-Hour Postload Plasma Glucose Level. Obstet Gynecol (2004) 104:1301-6. doi: 10.1097/01.AOG.0000142716.00040.bb

20. Retnakaran R, Zinman B, Connelly PW, Sermer M, Hanley AJ. Impaired Glucose Tolerance of Pregnancy is a Heterogeneous Metabolic Disorder as Defined by the Glycemic Response to the Oral Glucose Tolerance Test. Diabetes Care (2006) 29:57-62. doi: 10.2337/diacare.29.01.06.dc05-1404

21. Retnakaran R, Qi Y, Sermer M, Connelly PW, Zinman B, Hanley AJ. Isolated Hyperglycemia At 1 Hour on Oral Glucose Tolerance Test in Pregnancy Resembles Gestational Diabetes Mellitus in Predicting Postpartum Metabolic Dysfunction. Diabetes Care (2008) 31:1275-81. doi: 10.2337/dc08-0126

22. Scholtens DM, Kuang A, Lowe LP, Hamilton J, Lawrence JM, Lebenthal Y, et al. Hyperglycemia and Adverse Pregnancy Outcome Follow-Up Study (Hapo FUS): Maternal Glycemia and Childhood Glucose Metabolism. Diabetes Care (2019) 42:381-92. doi: 10.2337/dc18-2021

23. Lekva T, Bollerslev J, Norwitz ER, Aukrust P, Henriksen T, Ueland T. Aortic Stiffness and Cardiovascular Risk in Women With Previous Gestational Diabetes Mellitus. PloS One (2015) 10:e0136892. doi: 10.1371/journal.pone.0136892

24. Retnakaran R, Qi Y, Sermer M, Connelly PW, Hanley AY, Zinman B. The Postpartum Cardiovascular Risk Factor Profile of Women With Isolated Hyperglycemia At 1-Hour on the Oral Glucose Tolerance Test in Pregnancy. Nutr Metab Cardiovasc Dis (2011) 21:706-12. doi: 10.1016/ j.numecd.2011.02.010 
25. Gungor O, Gungor O, Gazi E, Ozkececi G, Cakir Gungor AN, Cevizci S, et al. Is Abnormal Glucose Metabolism During Pregnancy Related to Endothelial Dysfunction? J Matern Fetal Neonatal Med (2015) 28:182-5. doi: 10.3109/ 14767058.2014.906574

26. Göbl CS, Bozkurt L, Prikoszovich T, Tura A, Pacini G, Kautzky-Willer A. Estimating the Risk After Gestational Diabetes Mellitus: can We Improve the Information From the Postpartum OGTT? Am J Physiol Endocrinol Metab (2013) 304:E524-30. doi: 10.1152/ajpendo.00461.2012

27. Tumminia A, Milluzzo A, Cinti F, Parisi M, Tata F, Frasca F, et al. Abnormal 1-Hour Post-Load Glycemia During Pregnancy Impairs Post-Partum Metabolic Status: A Single-Center Experience. J Endocrinol Invest (2018) 41:567-73. doi: 10.1007/s40618-017-0774-z

28. HAPO Study Cooperative Research Group, Metzger BE, Lowe LP, Dyer AR, Trimble ER, Chaovarindr U, et al. Hyperglycemia and Adverse Pregnancy Outcomes. N Engl J Med (2008) 358:1991-2002. doi: 10.1056/ NEJMoa0707943

29. Kim HS, Chang KH, Yang JI, Yang SC, Lee HJ, Ryu HS. Clinical Outcomes of Pregnancy With One Elevated Glucose Tolerance Test Value. Int J Gynecol Obstet (2002) 78:131-8. doi: 10.1016/S0020-7292(02)00129-7

30. Corrado F, Di Benedetto A, Cannata ML, Cannizzaro D, Giornato D, Indorato G, et al. A Single Abnormal Value of the Glucose Tolerance Test is Related to Increased Adverse Perinatal Outcome. J Maternal-Fetal Neonatal Med (2009) 22:597-601. doi: 10.1080/14767050902801801

31. Kadakia R, Nodzenski M, Talbot O, Kuang A, Bain JR, Muehlbauer MJ, et al. Maternal Metabolites During Pregnancy are Associated With Newborn Outcomes and Hyperinsulinaemia Across Ancestries. Diabetologia (2019) 62:473-84. doi: 10.1007/s00125-018-4781-1

32. Mello G, Parretti E, Cioni R, Lucchetti R, Carignani L, Martini E, et al. The 75Gram Glucose Load in Pregnancy: Relation Between Glucose Levels and Anthropometric Characteristics of Infants Born to Women With Normal Glucose Metabolism. Diabetes Care (2003) 26:1206-10. doi: 10.2337/ diacare.26.4.1206

33. Weiss PAM. Diabetes in Pregnancy: Lessons From the Fetus. In: A Dornhorst, DR Hadden, editors. Diabetes and Pregnancy: An International Approach to Diagnosis and Management. Chichester, UK: Wiley \& Sons (1996). p. 221-40.

34. Desoye G, Nolan CG. The Fetal Glucose Steal: An Underappreciated Phenomenon in Diabetic Pregnancy. Diabetologia (2016) 59:1089-94. doi: 10.1007/s00125-016-3931-6

35. Retnakaran R, Qi Y, Sermer M, Connelly PW, Hanley AJ, Zinman B. An Abnormal Screening Glucose Challenge Test in Pregnancy Predicts Postpartum Metabolic Dysfunction, Even When the Antepartum Oral Glucose Tolerance Test is Normal. Clin Endocrinol (Oxf) (2009) 71:208-14. doi: 10.1111/j.1365-2265.2008.03460.x

36. Josefson JL, Scholtens DM, Kuang A, Catalano PM, Lowe LP, Dyer AR, et al. Newborn Adiposity and Cord Blood C-Peptide as Mediators of the Maternal Metabolic Environment and Childhood Adiposity. Diabetes Care (2021) 44:1194-202. doi: $10.2337 / \mathrm{dc} 20-2398$

37. Vlachopoulos C, Aznaouridis K, Stefanadis C. Prediction of Cardiovascular Events and All-Cause Mortality With Arterial Stiffness: A Systematic Review and Meta-Analysis. J Am Coll Cardiol (2010) 55:1318-27. doi: 10.1016/j.jacc. 2009.10.061

38. Liu H, Zhang C, Zhang S, Wang L, Leng J, Liu D, et al. Prepregnancy Body Mass Index and Weight Change on Postpartum Diabetes Risk Among Gestational Diabetes Women. Obes (Silver Spring) (2014) 22:1560-7. doi: 10.1002/oby. 20722

39. Fan Y, Li W, Liu H, Wang L, Zhang S, Li W, et al. Effects of Obesity and a History of Gestational Diabetes on the Risk of Postpartum Diabetes and Hyperglycemia in Chinese Women: Obesity, GDM and Diabetes Risk. Diabetes Res Clin Pract (2019) 156:107828. doi: 10.1016/j.diabres.2019.107828

40. Johansson K, Stephansson O, Neovius M. Outcomes of Pregnancy After Bariatric Surgery. N Engl J Med (2015) 372:2267. doi: 10.1056/ NEJMoa1405789

41. González I, Rubio MA, Cordido F, Bretón I, Morales MJ, Vilarrasa N, et al. Maternal and Perinatal Outcomes After Bariatric Surgery: A Spanish Multicenter Study. Obes Surg (2015) 25:436-42. doi: 10.1007/s11695-0141387-7

42. Feichtzinger M, Stopp T, Hofmann S, Springer S, Pils S, Kautzky-Willer A, et al. Altered Glucose Profiles and Risk for Hypoglycaemia During Oral
Glucose Tolerance Testing in Pregnancies After Gastric Bypass Surgery. Diabetologia (2017) 60:153-7. doi: 10.1007/s00125-016-4128-8

43. Busetto L, Dicker D, Azran C, Batterham RL, Farpour-Lambert N, Fried M, et al. Obesity Management Task Force of the European Association for the Study of Obesity Released "Practical Recommendations for the Post-Bariatric Surgery Medical Management”. Obes Surg (2018) 28:2117-21. doi: 10.1007/ s11695-018-3283-z

44. National Collaborating Centre for Women's and Children's Health (UK). Diabetes in Pregnancy: Management of Diabetes and Its Complications From Preconception to the Postnatal Period. London: National Institute for Health and Care Excellence (UK (2015).

45. Abdul-Ghani MA, Williams K, DeFronzo RA, Stern M. What is the Best Predictor of Future Type 2 Diabetes? Diabetes Care (2007) 30:1544-8. doi: $10.2337 / \mathrm{dc} 06-1331$

46. Abdul-Ghani MA, Abdul-Ghani T, Ali N, DeFronzo RA. One- Hour Plasma Glucose Concentration and the Metabolic Syndrome Identify Subjects AtHigh Risk for Future Type 2 Diabetes. Diabetes Care (2008) 31:1650-5. doi: $10.2337 / \mathrm{dc} 08-0225$

47. Abdul-Ghani MA, Lyssenko V, Tuomi T, DeFronzo RA, Groop L. Fasting Versus Postload Plasma Glucose Concentration and the Risk for Future Type 2 Diabetes: Results From the Botnia Study. Diabetes Care (2009) 32:281-6. doi: $10.2337 / \mathrm{dc} 08-1264$

48. Fiorentino TV, Marini MA, Andreozzi F, Arturi F, Succurro E, Perticone M, et al. One- Hour Post-Load Hyperglycemia is a Stronger Predictor of Type 2 Diabetes Than Impaired Fasting Glucose. J Clin Endocrinol Metab (2015) 100:3744-51. doi: 10.1210/jc.2015-2573

49. Alyass A, Almgren P, Akerlund M, Dushoff J, Isomaa B, Nilsson P, et al. Modelling of OGTT Curve Identifies $1 \mathrm{H}$ Plasma Glucose Level as a Strong Predictor of Incident Type 2 Diabetes: Results From Two Prospective Cohorts. Diabetologia (2015) 58:87-97. doi: 10.1007/ s00125-014-3390-x

50. Bergman M, Chetrit A, Roth J, Jagannathan R, Sevick M, Dankner R. Onehour Post-Load Plasma Glucose Level During the OGTT Predicts Dysglycemia: Observations From the 24year Follow-Up of the Israel Study of Glucose Intolerance, Obesity and Hypertension. Diabetes Res Clin Pract (2016) 120:221-8. doi: 10.1016/j.diabres.2016.08.013

51. Bergman M, Abdul-Ghani M, DeFronzo RA, Manco M, Sesti G, Fiorentino TV, et al. Review of Methods for Detecting Glycemic Disorders. Diabetes Res Clin Pract (2020) 165:108233. doi: 10.1016/ j.diabres.2020.108233

52. Bianchi C, Miccoli R, Trombetta M, Giorgino F, Frontoni S, Faloia E, et al. Elevated 1-Hour Postload Plasma Glucose Levels Identify Subjects With Normal Glucose Tolerance But Impaired B-Cell Function, Insulin Resistance, and Worse Cardiovascular Risk Profile: The GENFIEV Study. J Clin Endocrinol Metab (2013) 98:2100-5. doi: 10.1210/jc.20123971

53. Manco M, Panunzi S, Macfarlane DP, Golay A, Melander O, Konrad T, et al. Relationship Between Insulin Sensitivity and Cardiovascular Risk (Risc) Consortium. One- Hour Plasma Glucose Identifies Insulin Resistance and Beta-Cell Dysfunction in Individuals With Normal Glucose Tolerance: CrossSectional Data From the Relationship Between Insulin Sensitivity and Cardiovascular Risk (RISC) Study. Diabetes Care (2010) 33:2090-7. doi: $10.2337 / \mathrm{dc} 09-2261$

54. Marini MA, Succurro E, Frontoni S, Mastroianni S, Arturi F, Sciacqua A, et al. Insulin Sensitivity, B-Cell Function, and Incretin Effect in Individuals With Elevated 1-Hour Postload Plasma Glucose Levels. Diabetes Care (2012) 35:868-72. doi: 10.2337/dc11-2181

55. Succurro E, Pedace E, Andreozzi F, Papa A, Vizza P, Fiorentino TV, et al. Reduction in Global Myocardial Glucose Metabolism in Subjects With 1Hour Postload Hyperglycemia and Impaired Glucose Tolerance. Diabetes Care (2020) 43:669-76. doi: 10.2337/dc19-1975

56. Retnakaran R, Ye C, Hanley AJ, Connelly PW, Sermer M, Zinman B. Screening Glucose Challenge Test in Pregnancy can Identify Women With an Adverse Postpartum Cardiovascular Risk Factor Profile: Implications for Cardiovascular Risk Reduction. J Am Heart Assoc (2019) 8:e014231. doi: 10.1161/JAHA.119.014231

57. Bergman M, Chetrit A, Roth J, Dankner R. One-Hour Post-Load Plasma Glucose Level During the OGTT Predicts Mortality: Observations From the 
Israel Study of Glucose Intolerance, Obesity and Hypertension. Diabetes Med (2016) 33:1060-6. doi: 10.1111/dme.13116

58. Fiorentino TV, Succurro E, Andreozzi F, Sciacqua A, Perticone F, Sesti G. One-hour Post-Load Hyperglycemia Combined With HbAlc Identifies Individuals With Higher Risk of Cardio- Vascular Diseases: Cross-Sectional Data From the CATAMERI Study. Diabetes Metab Res Rev (2019) 35:e3096. doi: 10.1002/dmrr.3096

59. Succurro E, Marini MA, Arturi F, Grembiale A, Lugarà M, Andreozzi F, et al. Elevated One-Hour Post-Load Plasma Glucose Levels Identifies Subjects With Normal Glucose Tolerance But Early Carotid Atherosclerosis. Atherosclerosis (2009) 207:245-9. doi: 10.1016/ j.atherosclerosis.2009.04.006

60. Sciacqua A, Maio R, Miceli S, Pascale A, Carullo G, Grillo N, et al. Association Between One-Hour Post-Load Plasma Glucose Levels and Vascular Stiffness in Essential Hypertension. PloS One (2012) 7:e44470. doi: 10.1371/ journal.pone.0044470
61. Franzago M, Fraticelli F, Di Nicola M, Bianco F, Marchetti D, Celentano C, et al. Early Subclinical Atherosclerosis in Gestational Diabetes: The Predictive Role of Routine Biomarkers and Nutrigenetic Variants. J Diabetes Res (2018) 2018:9242579. doi: 10.1155/2018/9242579

Conflict of Interest: The authors declare that the research was conducted in the absence of any commercial or financial relationships that could be construed as a potential conflict of interest.

Copyright $\odot 2021$ Succurro, Fraticelli, Franzago, Fiorentino, Andreozzi, Vitacolonna and Sesti. This is an open-access article distributed under the terms of the Creative Commons Attribution License (CC BY). The use, distribution or reproduction in other forums is permitted, provided the original author(s) and the copyright owner(s) are credited and that the original publication in this journal is cited, in accordance with accepted academic practice. No use, distribution or reproduction is permitted which does not comply with these terms. 